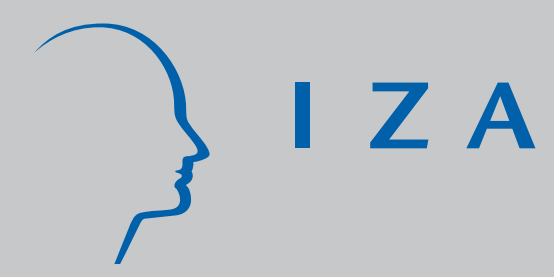

IZA DP No. 2500

Reciprocity and Payment Schemes:

When Equality Is Unfair

\author{
J ohannes Abeler \\ Steffen Altmann \\ Sebastian Kube \\ Matthias Wibral \\ December 2006
}




\title{
Reciprocity and Payment Schemes: When Equality Is Unfair
}

\author{
Johannes Abeler \\ IZA Bonn and University of Bonn \\ Steffen Altmann \\ IZA Bonn and University of Bonn \\ Sebastian Kube \\ University of Karlsruhe \\ Matthias Wibral \\ IZA Bonn and University of Bonn
}

\section{Discussion Paper No. 2500 \\ December 2006}

\author{
IZA \\ P.O. Box 7240 \\ 53072 Bonn \\ Germany \\ Phone: +49-228-3894-0 \\ Fax: +49-228-3894-180 \\ E-mail: iza@iza.org
}

\begin{abstract}
Any opinions expressed here are those of the author(s) and not those of the institute. Research disseminated by IZA may include views on policy, but the institute itself takes no institutional policy positions.

The Institute for the Study of Labor (IZA) in Bonn is a local and virtual international research center and a place of communication between science, politics and business. IZA is an independent nonprofit company supported by Deutsche Post World Net. The center is associated with the University of Bonn and offers a stimulating research environment through its research networks, research support, and visitors and doctoral programs. IZA engages in (i) original and internationally competitive research in all fields of labor economics, (ii) development of policy concepts, and (iii) dissemination of research results and concepts to the interested public.
\end{abstract}

IZA Discussion Papers often represent preliminary work and are circulated to encourage discussion. Citation of such a paper should account for its provisional character. A revised version may be available directly from the author. 
IZA Discussion Paper No. 2500

December 2006

\section{ABSTRACT \\ Reciprocity and Payment Schemes: When Equality Is Unfair}

A growing literature stresses the importance of reciprocity, especially for employment relations. In this paper, we study the interaction of different payment modes with reciprocity. In particular, we analyze how equal wages affect performance and efficiency in an environment characterized by contractual incompleteness. In our experiment, one principal is matched with two agents. The principal pays equal wages in one treatment and can set individual wages in the other. We find that the use of equal wages elicits substantially lower efforts and efficiency. This is not caused by monetary incentives per se since under both wage schemes it is profit-maximizing for agents to exert high efforts. The treatment difference is rather driven by the fact that reciprocity is violated far more frequently in the equal wage treatment. Agents suffering from a violation of reciprocity subsequently withdraw effort. Our results suggest that individual reward and punishment opportunities are crucial for making reciprocity a powerful contract enforcement device.

JEL Classification: $\quad$ C92, J33, J41, M12, M52

Keywords: laboratory experiment, wage setting, wage equality, gift exchange, reciprocity, social norms, incomplete contracts, multiple agents

Corresponding author:

Johannes Abeler

IZA

P.O. Box 7240

D-53072 Bonn

Germany

E-mail: abeler@iza.org

\footnotetext{
Financial support from the Bonn Graduate School of Economics is gratefully acknowledged. We thank Rachel Croson, Lucie Dörner, Florian Englmaier, Ernst Fehr, Simon Gächter, Uri Gneezy, David Huffman, Michael Kosfeld, Peter Kuhn, Sandra Ludwig, Wolfgang Luhan, Bentley MacLeod, Clemens Puppe, Martin Sefton, Ferdinand von Siemens, Philipp Wichardt, Eyal Winter and especially Armin Falk and Felix Marklein for helpful discussions. Valuable comments were also received from seminar and conference participants in Alessandria, Barcelona, Bayreuth, Bonn, Budapest, Jena, Karlsruhe, Paris, Prague, Stockholm (Ratio Colloquium), Tilburg, Vienna, and Zurich.
} 
"To treat people fairly you have to treat people differently." Roy Roberts, at that time VP of General Motors ${ }^{1}$

\section{Introduction}

In recent years, a vast body of literature has stressed the influence of social norms on individual decision making processes. Especially reciprocity, i.e., the willingness to reward kind actions and punish unkind actions even at a cost, has proven to be a highly relevant norm (e.g., Fehr and Gächter 1998, Fehr and Gächter 2000, Fehr and Schmidt 2003). In employment relations, reciprocity can mitigate the enforcement problems of incomplete contracts: many agents repay a gift in the form of higher wages by providing higher efforts even in one-shot situations where no future gains can be expected (e.g., Fehr et al. 1997, Hannan et al. 2002, Fehr and Falk 2002 Maximiano et al. forthcoming). This "gift exchange" (Akerlof 1982) constitutes at least a partial solution to moral-hazard problems that are widespread in labor relations.

The potential of reciprocity as a contract enforcement device, however, is likely to depend on the institutions that shape the employment relation, above all the mode of payment. Yet little is known about the interaction of reciprocity with different payment modes. Exploring this interaction is crucial in order to understand under which pay scheme the efficiency-enhancing effects of reciprocity develop their full power. This is what this paper does. The specific wage institution we study is wage equality. In particular we address the following questions: Is wage equality an efficient payment scheme when contract enforcement relies on reciprocity? Do principals choose to pay equal wages if they are not constrained to? How does the mode of payment affect work morale? Are equal wages perceived as fairer compared to individual wages?

Paying equal wages to workers on the same level of a hierarchy is common practice in many firms (e.g., Medoff and Abraham 1980, Baker et al. 1988). Several reasons for equal wages have been brought forward, amongst them increased peer monitoring (Knez and Simester 2001) and lower transaction costs since contracts do not have to be negotiated with every worker individually (see also Prendergast 1999). In addition, a concern for fairness has been a main argument invoked to justify equal wages. It has been argued that differential pay of co-workers is considered unfair by workers, causes resentment and envy within the workforce, and ultimately lower performance (Akerlof and Yellen 1990, Bewley 1999, Milgrom and Roberts 1992). Equality is also often referred to in employer-union bargaining as being a cornerstone of a fair wage scheme.

We contribute to the discussion about equal wages by examining their impact on the effectiveness of reciprocity in enforcing incomplete contracts. Paying equal wages for

\footnotetext{
${ }^{1}$ Quoted in Baker et al. (1988).
} 
equal performance seems uncontroversial in this respect. But in real-life work relations this case is likely to be the exception rather than the rule. When workers differ in their performance the following questions need to be answered. Does reciprocity imply that the agent who works more should also get a higher payoff compared to his coworker? In other words, does the often-heard slogan "equal pay for equal work" also call for "unequal pay for unequal work"? If this is the case, does a high-performing agent become frustrated and decrease work effort under equal wages? ${ }^{2}$ How do lowperforming agents react? What are the consequences for efficiency?

Ideally, these questions would be examined in two work environments that differ only with respect to the payment mode. To come close to this ideal world, we introduce a simple and parsimonious laboratory experiment that allows us to analyze the interaction between the institution of wage equality and reciprocity. In the experiment, one principal is matched with two agents. In a first stage the agents exert costly effort. After observing their efforts, the principal pays them a wage. In the main treatment he can choose the level of the wage but he is obliged to pay the same wage to both agents (equal wage treatment or EWT). In the control treatment, the principal can wage discriminate between the two agents (individual wage treatment or IWT). In both treatments, neither efforts nor wages are contractible. Note that principals in the individual wage treatment are free to pay the same wage to both agents, i.e., the EWT is a special case of the IWT.

The main findings of the experiment are as follows. First, performance differs substantially between the EWT and the IWT: agents who are paid equal wages exert significantly lower efforts than agents who are paid individually. Effort levels are nearly twice as high under individual wages. In addition, efforts decline over time when equal wages are paid. Second, this strong treatment effect cannot be explained by differences in monetary incentives. The actual wage choices of principals imply that providing high effort levels is profitable for agents in both treatments. From a purely monetary viewpoint agents' behavior in both treatments should thus be similar. Third, we show that the frequent violation of the norm of reciprocity in the equal wage treatment can explain the effort differences between the treatments. In both treatments, agents who exert a higher effort and earn a lower payoff than their co-worker strongly decrease their effort in the next period. This pattern is very similar in both treatments. However, the norm of reciprocity is violated much more frequently under equal wages. Principals in the IWT understand the mechanisms of reciprocity quite well. When efforts differ they do pay different wages, rewarding the harder-working

\footnotetext{
${ }^{2}$ Lazear (1989) raises similar doubts about pay equality (p. 561): "It is common for both management and worker groups such as labor unions to express a desire for homogeneous wage treatment. The desire for similar treatment is frequently articulated as an attempt to preserve worker unity, to maintain good morale, and to create a cooperative work environment. But it is far from obvious that pay equality has these effects."
} 
agent with a higher payoff in most cases.

Agents' reactions cause completely different dynamics in the two treatments. Under equal wages, initially hard-working agents get discouraged and reduce their effort to the level of their low-performing co-workers. By contrast, in the individual wage treatment the high performers keep exerting high efforts while the low performers change their behavior and strongly increase their effort levels.

Our results suggest a psychological rationale for using individual wages. Subjects perceive equal wages for unequal performance as unfair and reduce their effort subsequently. The traditional literature on incentive provision in groups comes to a similar conclusion though for a different reason. It is usually argued that the inefficiency of equal wages stems from the fact that marginal products and wages are not aligned. This can lead to free-riding among selfish agents (e.g., Holmström 1982, Erev et al. 1993). We enlarge the scope of this critical view on wage equality: interestingly, in our setup it is precisely the presence of reciprocal agents and not their absence that calls for the use of individual rewards.

Since agents in our experiment compare their payoff with the payoff of their co-worker, our results also inform the literature analyzing the influence of relative income on satisfaction and performance. It has been shown that relative income affects people's well-being (e.g., Clark and Oswald 1996, Easterlin 2001). However, it is less clear how this influences performance, i.e., whether low relative income leads to frustration and reduced performance (as in Clark et al. 2006 and Torgler et al. 2006) or to an increase in performance due to a "positional arms race" (Neumark and Postlewaite 1998, Layard 2005, Bowles and Park 2005). The controlled laboratory environment of our experiment allows us to reconcile these differing views. Our results indicate that the comparison process goes beyond a one-dimensional comparison of income and also includes a comparison of effort. In particular, they suggest that receiving a lower income while exerting a higher effort leads to reduced performance which is likely to be driven by feelings of exploitation. By contrast, a lower income that is generated by a lower effort leads to a (small) increase in performance.

There are only a few experimental studies that analyze the interaction of payment modes and social preferences when contracts are incomplete. ${ }^{3}$ Fehr et al. (forthcoming) let principals choose between contracts relying on explicit incentives and "bonus contracts" relying on trust and reciprocity. In a bilateral setup, they find that a bonus contract oftentimes yields a higher efficiency than the incentive contract. Most closely related to our paper is the work of Charness and Kuhn (2005). Here, one principal is

\footnotetext{
${ }^{3}$ Theoretical analyses of this interaction are provided by, for example, Demougin and Fluet (2003), Bartling and von Siemens (2004a, 2004b), and Itoh (2004). All these models rely on purely distributive (outcome-based) preferences like envy or inequality aversion. For most cases they do not predict that equal wages do lead to lower effort exertion as it is the case in our experiment.
} 
matched with two agents differing in productivity; like in our study, wages and efforts are not contractible. In contrast to our results, they find that co-workers' wages do not matter much for agents' decisions. However, their design differs from ours in several important points. While Charness and Kuhn focus on heterogeneity in productivity, we look at the effect of actual output differences between agents. Furthermore, we allow for richer comparisons between the agents, as in their design agents are not aware of the magnitude and direction of the productivity differences. The different results underline the importance of information for determining the reference group: Charness and Kuhn's results rather apply to groups of workers that are loosely related and know little about each other, while our focus is on close co-workers who have a good understanding about their peers' abilities and efforts.

Regarding compensation practice in firms, our findings highlight the importance of taking the concerns for co-workers' wages into account. However, doing so by paying equal wages to a group of agents may actually do more harm than good. As soon as agents differ in their performance, equal wages which seem to be a fair institution at first sight might be considered very unfair. While the discouraging effect of equal wages on hard-working agents has long been informally discussed (e.g., Milgrom and Roberts 1992) this paper provides controlled evidence in favor of this intuition. Moreover, it suggests that it is the violation of reciprocity that causes the discouragement and low performance. Our results should not be interpreted as arguments against wage equality in general but they rather point to limits of equal wages. Wage equality is potentially a good choice in occupations where, e.g., due to technological reasons, workers' performance differs only slightly or where performance differences are due to random influences. In addition, the transparency of co-workers' work efforts and wages might have an influence on the optimal choice of the pay scheme.

The remainder of this paper is structured as follows. In the next section we describe the experimental design and discuss theoretical predictions. In section 3 we present and discuss results and section 4 concludes.

\section{Experimental Setup}

\section{$2.1 \quad$ Experimental Design}

In the experiment, one principal is matched with two agents. The subjects play a twostage game. In the first stage, the agents decide simultaneously and independently how much effort they want to exert. Exerting effort is costly for the agents. Effort choices range from 1 to 10 and are associated with a convex cost function displayed in Table 1. The principal reaps the benefits of production: every unit of effort increases his payoff by 10 . 


\begin{tabular}{|r|r|r|r|r|r|r|r|r|r|r|}
\hline Effort level $e_{i}$ & 1 & 2 & 3 & 4 & 5 & 6 & 7 & 8 & 9 & 10 \\
\hline Cost of effort $c\left(e_{i}\right)$ & 0 & 1 & 2 & 4 & 6 & 8 & 10 & 13 & 16 & 20 \\
\hline
\end{tabular}

Table 1: Cost of effort.

In the second stage, after observing the effort decisions of the agents in his group, the principal decides on wages for the two agents. The wages have to be between 0 and 100. Neither efforts nor wages are contractible. The only difference between the treatments is the mode of payment. In our main treatment the principal can only choose one wage $w$ that is paid to each of the agents (equal wage treatment or EWT). In the control treatment he can discriminate between the two agents by choosing wages $w_{1}$ and $w_{2}$ for agent 1 and 2, respectively (individual wage treatment or IWT). The EWT is thus a special case of the IWT. At the end of each period, the two agents and the principal are informed about efforts, wage(s), and the resulting payoffs for all three players. The payoff functions for the players are summarized in Table 2.

\begin{tabular}{|r|c|c|}
\hline Treatment & EWT & IWT \\
\hline Payoff Principal & $\pi_{P}=10\left(e_{1}+e_{2}\right)-2 w$ & $\pi_{P}=10\left(e_{1}+e_{2}\right)-\left(w_{1}+w_{2}\right)$ \\
\hline Payoff Agent $i$ & $\pi_{A_{i}}=w-c\left(e_{i}\right)$ & $\pi_{A_{i}}=w_{i}-c\left(e_{i}\right)$ \\
\hline
\end{tabular}

Table 2: Payoffs of players.

This game is played for twelve periods. We implemented a stranger design to abstract from confounding reputation effects, i.e., at the beginning of each period principals and agents were rematched anonymously and randomly within a matching group. A matching group consisted of three principals and six agents. The subjects kept their roles throughout the entire experiment. After the last period, subjects answered a questionnaire. The experiment was conducted in a labor market framing, i.e., principals were called "employers" and agents were called "employees". ${ }^{4}$

Our setup is related to the gift-exchange game (Fehr et al. 1993) but differs in two important ways. First, a principal is matched with two agents instead of one. This is an essential prerequisite to analyze the interaction between the institution of wage equality and reciprocity. Additionally, the agents move first while in most experiments the principal moves first. Our move order allows the principal to base his wage decision on the actually exerted effort. ${ }^{5}$

\footnotetext{
${ }^{4}$ An English translation of the instructions is available from the authors upon request.

${ }^{5}$ For an experiment in which principals move first and decide according to productivity differences, see Charness and Kuhn (2005). See Gneezy (2006) for a direct comparison of move orders.
} 
All participants started the experiment with an initial endowment of 400 points that also served as their show-up fee. Points earned were converted at an exchange rate of 0.01 Euro/point. The experiment was conducted at the BonnEconLab at the University of Bonn in April 2005 using z-Tree (Fischbacher 1999). For each treatment, we ran four sessions with a total of 8 matching groups (144 participants). The experiment lasted approximately 70 minutes. On average subjects earned 8.30 Euro including the show-up fee of 4 Euro.

\subsection{Behavioral Predictions}

Efficiency is determined by agents' effort choices. It is maximized if both agents exert the highest possible effort of 10 . However, if all players are rational and selfish the principal will not pay anything to the agents since wage payments only reduce his monetary payoff. Anticipating this, both agents will provide the minimal effort of one in the first stage. The finite repetition of the game in randomly rematched groups does not change this prediction. This subgame perfect equilibrium is the same for both payment modes. If all players were selfish we should therefore expect no difference between treatments.

By contrast, in laboratory experiments studying labor relations with incomplete contracts, one typically observes that efforts and wages exceed the smallest possible value. Moreover, wages and efforts are positively correlated (e.g., Fehr and Gächter 2000). These stylized facts can be explained with a preference for reciprocity, i.e., players reward kind actions of other players and punish unkind actions, even if they have to incur a cost for the reward or punishment. This implies that a higher effort will be rewarded with a higher wage. More importantly, the two treatments of our experiment can yield different outcomes if players are reciprocal. In our three-player setup, reciprocity might imply that the agent who works more also should get a higher payoff compared to his co-worker. ${ }^{6}$ This is not possible under wage equality when agents differ in their performance. Since agents are paid the same wage and have to bear the cost of effort exertion, the agent who exerted a higher effort receives a lower net payoff and feels exploited. Providing an additional unit of effort increases the risk of being exploited and therefore constitutes a disincentive to provide effort for reciprocal agents under equal wages. ${ }^{7}$

\footnotetext{
${ }^{6}$ Note that this concept of reciprocity does not solely rely on intentions of the principal but rather captures procedural fairness more generally (cf. Dufwenberg and Kirchsteiger 2004 or Falk and Fischbacher 2006 for formal models of reciprocity).

${ }^{7}$ The co-worker of an exploited agent may also experience some disutility. He works less but earns more than his colleague, so he could feel guilty about this undeserved profit. However, it is reasonable to assume that a disadvantageous norm violation (exploitation) is experienced more strongly than an advantageous norm violation (guilt). Support for this assumption can be found in, e.g., Loewenstein et al. (1989) and Babcock et al. (1996).
} 
On the contrary, in the individual wage treatment it is always possible for a principal to fulfill the norm of reciprocity. He can set the wages such that the hard-working agent gets a higher payoff. If principals mostly do so, one will observe fewer norm violations in the IWT than in the EWT. If agents react similarly to norm violations in both treatments, efforts in the EWT should be lower than under individual wages. ${ }^{8}$

\section{Results}

In this section we present the results of the experiment and discuss possible explanations for the observed behavior. We first analyze the efficiency implications of the two payment schemes by comparing the effort choices of agents. We then explore possible reasons for the effort choices by analyzing how the mode of pay affects monetary incentives and interacts with the social preferences of the agents.

\subsection{Effort Choices and Efficiency}

Figure 1 shows the development of average efforts over time. Two things are striking about the graph. First, efforts are considerably lower in the equal wage treatment. While agents in the IWT on average exert an effort of 8.21, agents in the EWT only provide an effort of 4.40 (Mann-Whitney test: $p<0.01$ ). ${ }^{9}$ Second, efforts decrease over time under equal wages which is not the case when individual wages are paid (Wilcoxon test for periods 1-6 against 7-12: IWT, $p=0.56$; EWT, $p<0.01$ ). This means that the effort difference under the two wage schemes becomes even larger during the experiment. The treatment difference is also present when individual matching groups are considered: the highest average effort of an EWT matching group (5.88) is still lower than the lowest average effort of an IWT matching group (7.47).

The difference in agents' behavior can also be seen in the histogram of effort choices (Figure 2). In the individual wage treatment agents choose the maximum effort of 10 in $49 \%$ of the cases, $84 \%$ of the choices are higher than 6 . Under equal wages, agents choose an effort higher than 6 in only $26 \%$ of all cases. The effort decisions are more spread out in the EWT, the minimal effort of 1 being the modal choice with $24 \%$ of the choices.

The comparison of effort levels across treatments shows that the enforcement power of reciprocity strongly depends on the wage scheme that is used. Under equal wages,

\footnotetext{
${ }^{8}$ Other models of social preferences assume that players do not care about reciprocity per se but dislike unequal payoffs, e.g., the model by Fehr and Schmidt (1999). Using their preferred parameters, their model predicts the same outcome in our game as the subgame perfect Nash equilibrium: minimal wages $(w=0)$ and minimal efforts $(e=1)$. Assuming extreme values for the guilt parameter $(\beta>2 / 3$ for $40 \%$ of subjects) does not change this result by much. In this case, the model predicts an average effort of 1.6. This prediction is the same for both treatments. Calculations are available upon request.

${ }^{9}$ Unless otherwise noted, all tests use matching group averages as independent observations.
} 


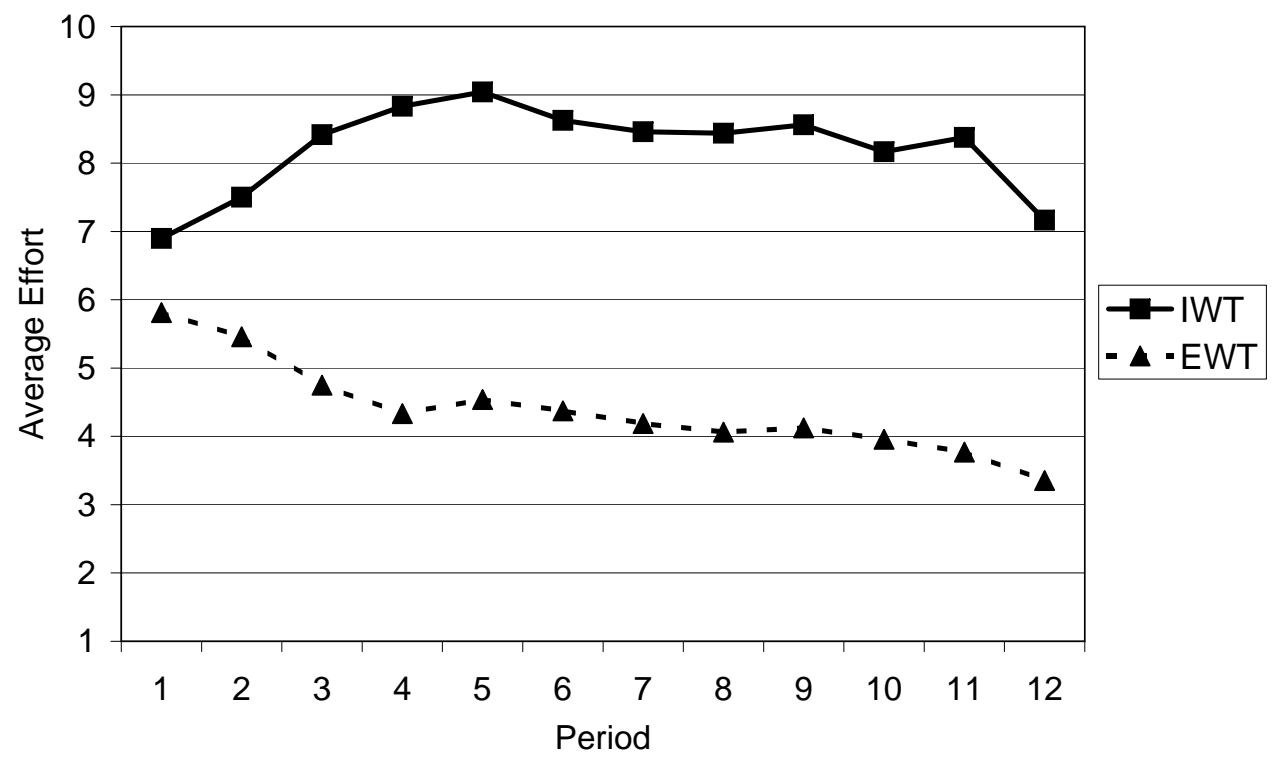

Figure 1: Average effort per period. The effort is aggregated per period over all matching groups.

efforts are relatively low, reaching only about half the level of efforts in the IWT. At the same time, the individual wage institution is very successful in eliciting efforts. Although contracts are not enforceable at all, efforts are close to the maximum in the IWT. Since higher efforts increase production and since the marginal product of effort always exceeds its marginal cost, the differences in effort provision directly translate into differences in efficiency.

Result 1: The two payment modes exhibit strong differences with respect to the performance they elicit: agents who are paid equal wages exert significantly lower efforts than agents who are paid individually. This results in a much higher efficiency under individual wages.

Both, the agents and the principals benefit from the increase in efficiency. The average period profit of a principal is 56 in the EWT compared to 100 in the IWT (MannWhitney test: $p<0.01$ ), while agents earn an average period profit of 10 under equal wages vs. 17 under individual wages (Mann-Whitney test: $p<0.01) .{ }^{10}$

\subsection{Wage Setting and Monetary Incentives}

In order to better understand the vast differences in effort choices, we now take a closer look at principals' wage setting and the resulting monetary incentives for the agents under the two payment schemes. Figure 3 plots the average wage per effort level in the

\footnotetext{
${ }^{10}$ The large payoff difference between principals and agents is (at least partly) driven by to the two-to-one matching and the last-mover advantage of principals that has also been observed in other gift-exchange experiments (e.g., Fehr et al. (forthcoming)).
} 


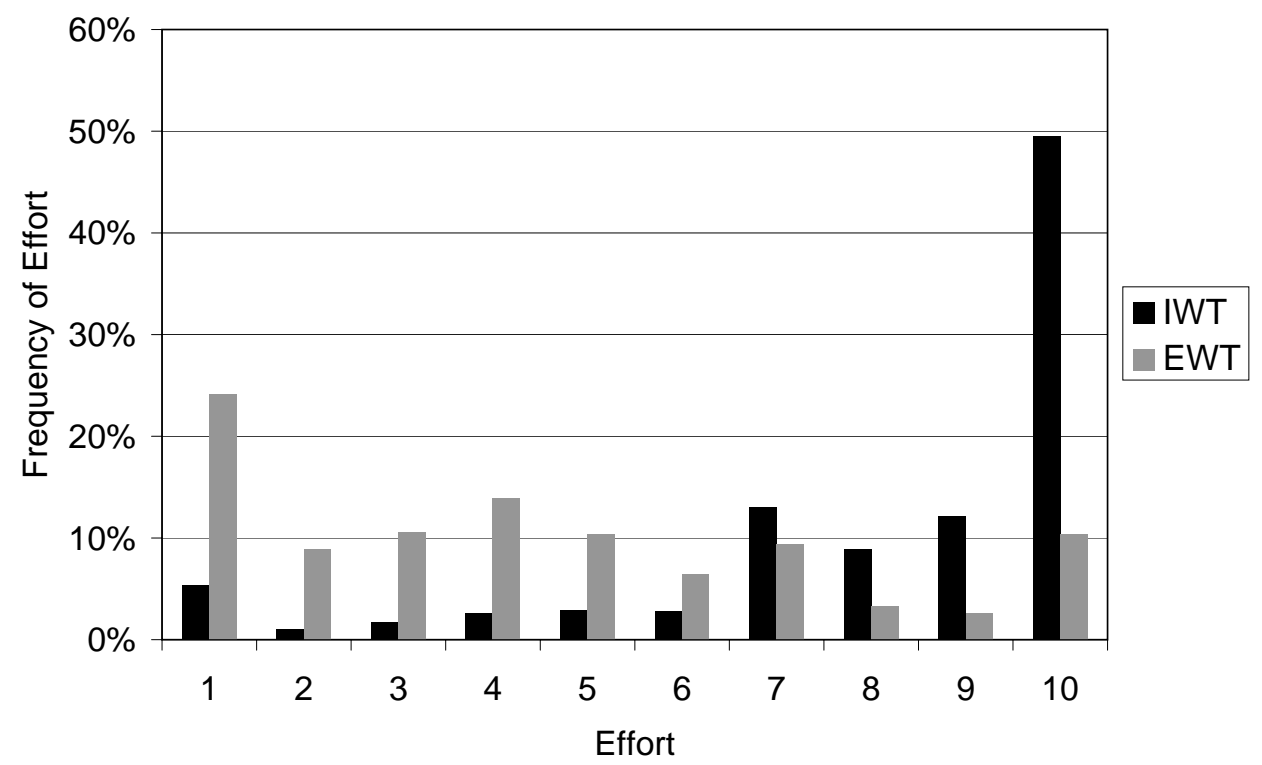

Figure 2: Frequency of effort choices.

two treatments. For both treatments we take the wage paid by the principal for each individual effort decision and calculate averages for a given effort level. ${ }^{11}$ The graph exhibits the upward sloping effort-wage relation of many gift-exchange experiments. For example, an agent in the equal wage treatment who exerts an effort of 1 receives on average a wage of 6.3 while an agent exerting an effort of 10 receives an average wage of 30.3. In the individual wage treatment, the corresponding wages are 1.7 and 39.5 .

The effort-wage relation indicates that principals are indeed reciprocal, i.e., they reward higher effort levels with higher wages. While this holds true in both treatments, some differences between the treatments are worth noting. First, the wage increase is somewhat steeper in the IWT. Moreover, the average wages in the EWT do not rise as steadily as in the IWT but fluctuate more strongly, especially for high effort levels. While this may partly be due to the low number of high effort observations in the EWT, it might also be caused by a stronger influence of the co-worker's effort $e_{j}$ on worker $i$ 's wage. We will turn to this point in more detail below.

Result 2: Principals reward a higher effort with a higher wage in both treatments.

The reciprocal behavior of the principals generates monetary incentives for agents. The potential of reciprocity to enforce incomplete contracts partly depends on these monetary incentives. Therefore, we will now explore the impact of the purely monetary

\footnotetext{
${ }^{11}$ Thus every wage decision of the principal enters twice in the equal wage treatment. In the IWT, principals can set two wages, and each of these wages enters the analysis once. Principals in the IWT do indeed use the possibility to set different wages. If efforts differ they also pay different wages in $91.4 \%$ of cases (see also Section 3.3.1).
} 


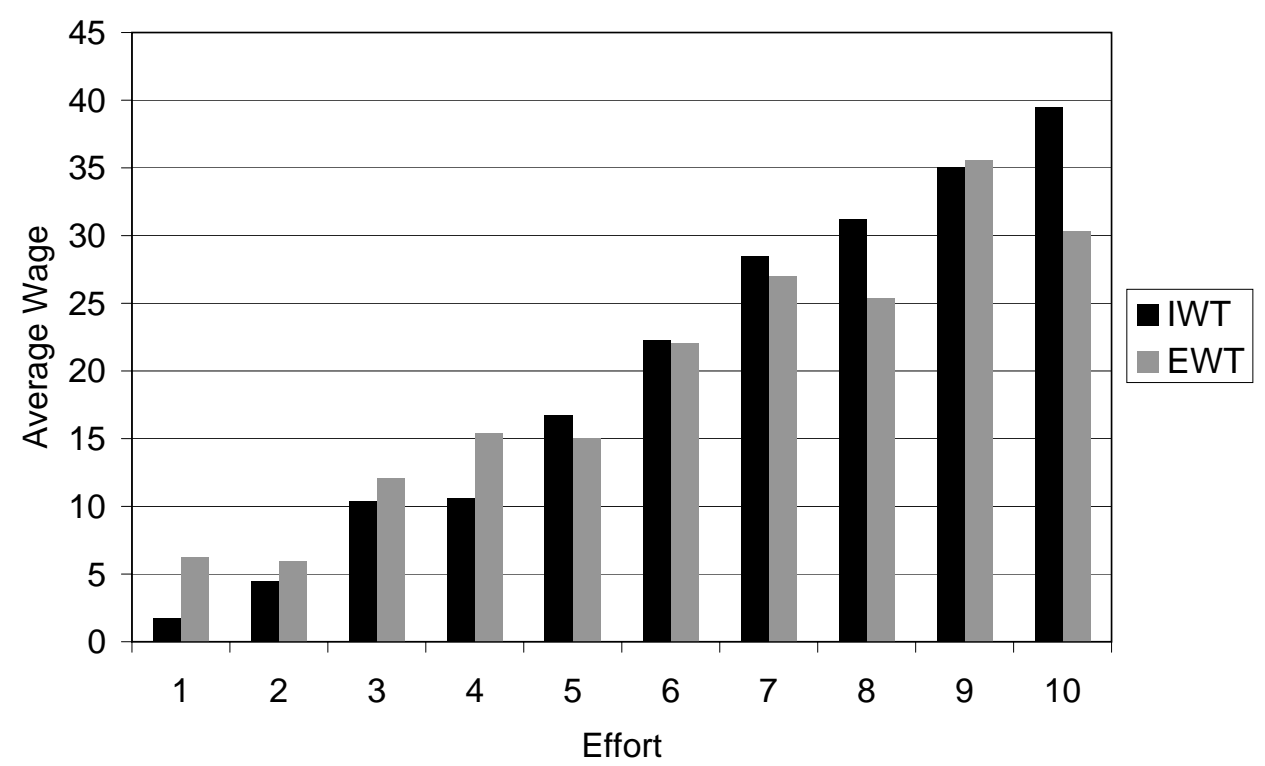

Figure 3: Average wage for a given effort.

incentives on agents' behavior, while bearing in mind that also non-monetary aspects of the payment schemes will be important for the agents (see Section 3.3).

In order to derive the monetary incentives entailed in the principals' wage decisions, one first has to take into account that the agents have to pay the cost of effort exertion (see Table 1). Qualitatively, this does not change the picture of the effort-wage relation: higher effort levels seem to lead not only to higher wages, but also to higher profits for the agents. In order to check this in more detail, we estimate a simple linear OLS-model where we regress the agent's (period) profit $\pi_{A_{i}}$ on his effort level $e_{i}$ and a constant. To account for potential differences between the treatments we include a treatment dummy $I W T$, and an interaction term of the treatment dummy and agent's effort. $I W T$ is equal to 1 for the individual wage treatment and equal to 0 for the equal wage treatment. The estimation results are reported in column 1 of Table $3{ }^{12}$ The coefficients indicate that the effort-profit relation is indeed positive in both treatments. On average, an additional unit of effort increases the agent's profit under equal wages by 1.031 points. This coefficient is weakly significant. In the individual wage treatment the effort-profit relation is slightly steeper: an effort increase of 1 leads to an increase in agent's profit of 1.804 points $(1.031+0.773)$. The difference between treatments, however, is not significant.

We speculated above that exerting high effort levels might be more risky for an agent under equal wages since the co-worker's effort has probably a stronger influence on the principal's wage payment. An agent under individual pay only bears the risks of

\footnotetext{
${ }^{12}$ We allow for dependent observations within matching groups and assume that only observations in different matching groups are independent. The reported robust standard errors are adjusted for this clustering.
} 


\begin{tabular}{lcc} 
Dep. Variable & $\pi_{A_{i}}$ & $\pi_{A_{i}}$ \\
\hline$e_{i}$ & $1.031^{*}$ & $0.854^{* *}$ \\
& $(0.535)$ & $(0.348)$ \\
$I W T \times e_{i}$ & 0.773 & $0.995^{*}$ \\
& $(0.615)$ & $(0.469)$ \\
cons & $5.927^{* *}$ & $-5.815^{* * *}$ \\
& $(2.614)$ & $(1.523)$ \\
$I W T$ & -3.744 & $11.004^{* * *}$ \\
& $(3.235)$ & $(3.274)$ \\
$e_{j}$ & & $2.774^{* * *}$ \\
& & $(0.280)$ \\
$I W T \times e_{j}$ & & $-3.178^{* * *}$ \\
& & $(0.403)$ \\
\hline N. Obs. & 576 & 576 \\
$R^{2}$ & 0.100 & 0.238
\end{tabular}

Table 3: Profit regressions. Robust standard errors are given in parentheses. The dummy "IWT" is equal to 1 for the individual wage treatment. Significance at the $10 \%, 5 \%$ and $1 \%$ level is denoted by $*{ }^{* *}$, and ${ }^{* * *}$, respectively.

contractual incompleteness, i.e., he risks meeting a principal who is not reciprocal and pays no (or a low) wage. Under equal wages, the agent additionally faces the risk of receiving a lower wage because his co-worker negatively influences the principal's wage decision. This might weaken the incentives to provide high efforts, especially for risk-averse agents. To check whether high effort provision nevertheless pays off individually, we estimate a second model where we control for the co-worker's effort $e_{j}$ (see Column 2 of Table 3). ${ }^{13}$ The results indicate that indeed the co-worker's effort choice has a substantial influence on an agent's profit under wage equality while it has a negligible influence if individual wages are paid. An increase in agent $j$ 's effort increases agent $i$ 's profit in a given period by 2.774 points in the EWT, while the influence in the IWT is $-0.404(=2.774-3.178) .{ }^{14}$ However, it is still individually profitable for the agents to exert high efforts in the EWT. An additional unit of (own) effort increases the agent's profit by 0.854 points.

The regression analysis suggests that exerting higher efforts is profitable for the agents under both wage schemes, at least if one averages over all observations in our sample.

\footnotetext{
${ }^{13}$ In order to estimate the influence of the co-worker's effort $e_{j}$ we have to split the sample such that only one observation per firm is included in the analysis. In order to make the two specifications comparable, we reported the first regression for the same sample. The results do not depend on which worker's effort is selected as " $e_{i}$ ".

${ }^{14} \mathrm{~A}$ separate regression for the IWT (not reported here) indicates that this value is not significant $(p=0.219)$.
} 


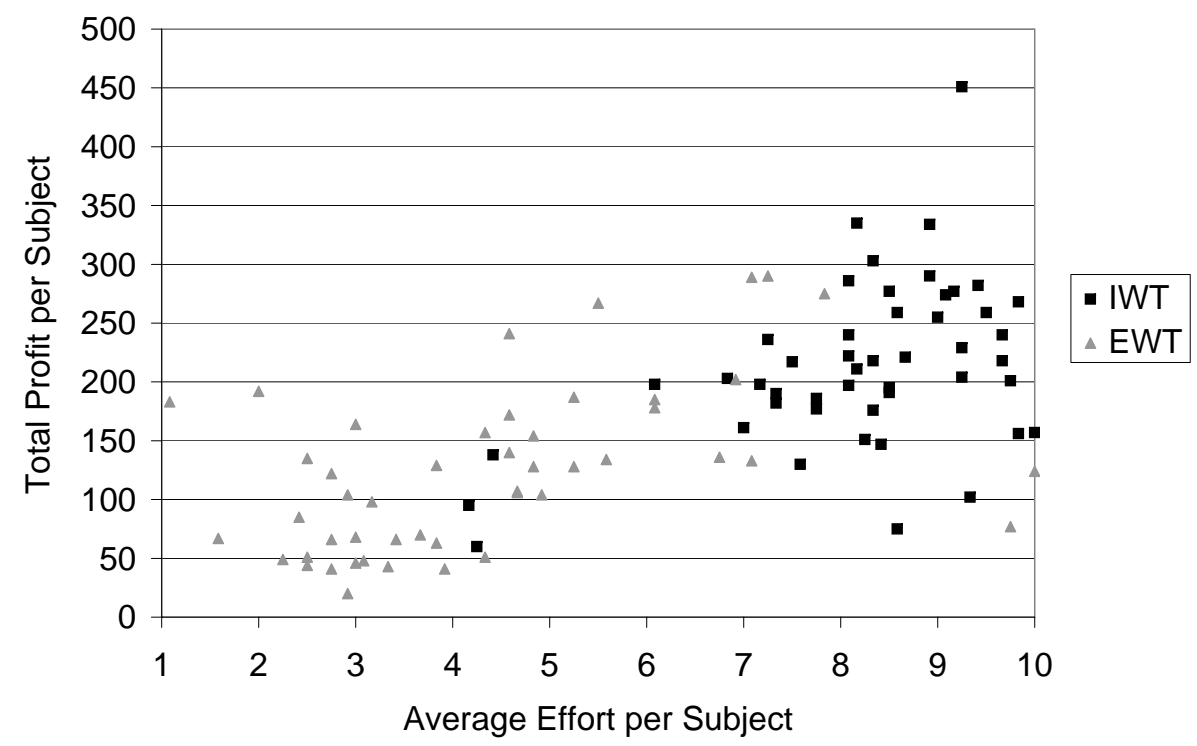

Figure 4: Total profits of agents given their average effort level over all periods.

We now analyze whether this also holds if we aggregate efforts and profits individually for each subject. In the scatter plot shown in Figure 4, the x-axis depicts the average effort of an agent that he exerted over the course of the 12 periods, the y-axis shows the sum of all profits of an agent. Each dot thus represents one subject. The picture confirms the previous impression: subjects who exerted a higher average effort level during the experiment earned higher profits in total. More importantly, for the (few) observations where agents provide similar average effort levels in the two treatments earnings are very similar, too. In light of this, the strong differences in actual efforts and especially the low effort levels under equal wages are remarkable.

One could object that the subjects in the experiment did not have access to the analyses we just presented. Both the regression analysis and the effort-profit relation of Figure 4 are "ex-post" examinations while the subjects only observed the behavior and outcomes of their previous groups. It could thus be that subjects were not able to learn that high efforts are profitable given the limited information they had. To explore if this is the case we calculate the profit-maximizing effort level for each agent in each period based on the information this subject actually has. The agent is assumed to choose the effort level that was on average the most profitable of all effort levels he has observed so far. ${ }^{15}$ The calculation shows that agents in the EWT could have increased their efforts and profits considerably even by using only their limited information. In the last period, the average profit-maximizing effort level exceeds the average actual level in that period by $61 \%$. By contrast, subjects in the IWT do find the profit-

\footnotetext{
${ }^{15}$ Since we assume that subjects do not "try" a never-observed effort level and since some subjects in the EWT never observe high effort levels in their group, this calculation underestimates the optimal effort level for the EWT.
} 
maximizing effort levels: the average actual effort levels in the IWT are very close to the profit-maximizing levels. Our findings concerning agents' monetary incentives can be summarized as follows.

Result 3: The wages paid by principals imply similar monetary incentives in both treatments. A higher effort leads to a higher profit in both treatments. The increase is only slightly stronger under individual wages.

While the analysis of the monetary incentives yielded some differences between the two wage schemes at hand, these differences can hardly explain the discrepancy in agents' performance reported above. Agents under individual wages provide very high effort levels, which is in line with the monetary incentives. On the other hand, agents under equal wages predominantly choose low efforts, thereby foregoing considerable profits. In light of these results, it is all the more important to analyze the non-monetary incentives of the two wage schemes in detail.

\subsection{Non-Monetary Incentives}

In the preceding section we presented evidence that many principals reciprocate a higher effort with a higher wage in both treatments. As discussed in Section 2.2 this is in line with the norm of reciprocity. However, reciprocal agents will additionally care about whether the worker who works more than his co-worker also receives a higher payoff than his colleague. A violation of this second aspect of reciprocity has different implications for the two agents involved. First, an agent who works more but does not receive a higher payoff than his co-worker suffers twice: he feels unfairly treated and he earns less. Thus, we refer to this situation as disadvantageous norm violation. Analogously, his co-worker who exerts a lower effort and earns a higher profit faces an advantageous norm violation since the unfairness is at least to his monetary advantage. ${ }^{16}$ These norm violations cause non-monetary incentives that reinforce or counteract the monetary incentives implied by the wage setting. The combination of these two types of incentives will determine how agents perform under the respective wage scheme.

\subsubsection{Agents' reactions to norm violations}

In the following, we analyze how agents change their effort provision after experiencing an advantageous or a disadvantageous norm violation. We will show that a norm violation leads to an overall decrease in effort. This effect is very similar in both treatments, however, the norm of reciprocity is violated much more frequently in the

\footnotetext{
${ }^{16}$ More precisely, an advantageous norm violation comprises all cases when efforts are equal but payoff is higher, or when effort is lower effort but payoff is not. A disadvantageous norm violation occurs if efforts are equal but profit is lower, or if effort is higher but profit is not.
} 


\begin{tabular}{|l|ccc||c|}
\hline & Effort Down & Effort Constant & Effort Up & N. Obs. \\
\hline \hline EWT & \multicolumn{3}{|c}{} & \\
No Violation & $19.1 \%$ & $54.4 \%$ & $26.5 \%$ & 68 \\
Adv. Violation & $12.2 \%$ & $43.5 \%$ & $44.3 \%$ & 230 \\
Disadv. Violation & $52.6 \%$ & $33.9 \%$ & $13.5 \%$ & 230 \\
\hline Total & $30.7 \%$ & $40.7 \%$ & $28.6 \%$ & 528 \\
\hline \hline IWT & & & & \\
No Violation & $19.2 \%$ & $51.8 \%$ & $29.0 \%$ & 448 \\
Adv. Violation & $45.0 \%$ & $27.5 \%$ & $27.5 \%$ & 40 \\
Disadv. Violation & $35.0 \%$ & $57.5 \%$ & $7.5 \%$ & 40 \\
\hline Total & $22.3 \%$ & $50.4 \%$ & $27.3 \%$ & 528 \\
\hline
\end{tabular}

Table 4: Frequency of effort reactions.

EWT.

Table 4 shows how often agents decrease, increase or do not change their effort from period $t$ to $t+1$ after they experienced no, an advantageous or a disadvantageous norm violation in period $t$. The top panel of Table 4 reports data for the equal wage treatment. When the norm is fulfilled, most agents keep their effort constant (54\%) and slightly more agents increase their effort than decrease it. After experiencing an advantageous violation of reciprocity, agents tend to increase their effort (44\%) and only few reduce it (12\%). The opposite is true after a disadvantageous norm violation: the majority of agents decrease their effort $(53 \%)$ and only few increase their effort in the following period (14\%). These numbers suggest that agents dislike being exploited (disadvantageous norm violation) and dislike feeling guilty (advantageous norm violation). After a norm violation they change their effort provision in the direction that makes a violation less likely to occur in the next period. This is consistent with the predictions of reciprocity. ${ }^{17}$

Behavior in the individual wage treatment (bottom panel) is very similar to behavior in the EWT for the cases of no violation and disadvantageous violations. When the norm is not violated agents mostly keep their effort unchanged. After a disadvantageous norm violation efforts are decreased rather than increased, as in the EWT. The only difference between the treatments is observed when agents experience an advantageous norm violation: agents in the IWT tend to decrease their effort while the EWT agents tend to increase it in this case.

\footnotetext{
${ }^{17}$ Similar effects are observed by Thöni and Gächter (2005) in a related set-up. They allow agents to revise their effort decision after learning their co-workers' effort choice. In the revision stage, the majority of agents decreases the effort difference to their co-worker, i.e. agents with initially higher effort revise their decision downwards while agents with lower effort revise it upwards.
} 
If behavior is so similar between treatments, how can a preference for reciprocity cause the treatment effect? The last column of Table 4 shows how often the three situations occur in the two treatments. In the EWT, the norm is violated in $87 \%$ of all cases (460 out of 528) since this happens whenever agents exert different efforts. By contrast, in the IWT reciprocity is violated only in $15 \%$ of the cases (80 out of 528). Thus, even if the behavior in a given situation is similar, agents in the EWT are far more often exposed to norm violations than agents in the IWT. This is not caused by the principals per se. It is rather the heterogeneity in efforts combined with the equal wage institution that forces principals to set wages that are not in line with reciprocity. Principals in the IWT seem to understand the mechanisms of reciprocity quite well and use the possibility to set different wages in a sophisticated way. If efforts differ they also pay different wages in $91.4 \%$ of the cases, the more hard-working agent getting the higher wage in $98.8 \%$ of these cases. Additionally they do not treat agents differently if they exert the same effort: if efforts are equal, principals also pay equal wages in $90.1 \%$ of the cases. ${ }^{18}$

Result 4: Agents mostly react to disadvantageous violations of reciprocity by reducing their effort and by increasing it after an advantageous norm violation. The norm of reciprocity is far more often violated in the equal wage treatment.

So far we have seen that agents' reactions are largely in line with the hypothesized behavior of a reciprocal agent and that treatments differ with respect to the frequency of norm violations. Yet, this is not sufficient to explain the treatment effect, since a norm violation is always advantageous to the one agent and at the same time disadvantageous to the other one. If both agents adjust their effort in a similar way but in opposite directions the adjustments will cancel out. Reciprocity can only explain the downward trend in effort provision in the EWT if the reaction to a disadvantageous norm violation is stronger than the reaction to an advantageous one.

We therefore analyze the magnitude of agents' reactions to norm violations. Figure 5 shows the average change in effort provision from period $t$ to $t+1$ after an agent experienced no norm violation, a disadvantageous or an advantageous norm violation in period $t$. The width of the bars corresponds to the number of observations in

\footnotetext{
${ }^{18}$ We checked the robustness of the reaction patterns in several ways. For example, it could be possible that the results are driven by strong dynamics at the beginning of the experiment or by an end-game effect. The results stay however very similar if one restricts the analysis to the first or the second half of all periods. It could also be that agents react differently to norm violations if they are paid very high or low wages. However, performing the analysis only for agents receiving a wage out of the top or bottom quartile of the ex-post wage distribution does not alter the result. An implicit assumption of our analysis is that the gift-exchange relation is generally intact between principal and agent, i.e., that agents exert a non-minimal effort and that principals pay a positive wage. The results do not change if one restricts the analysis to these cases. Also if one defines gift exchange as requiring the agent's profit to be positive, i.e. $w_{i}>c\left(e_{i}\right)$ instead of $w_{i}>0$, the results are very similar.
} 


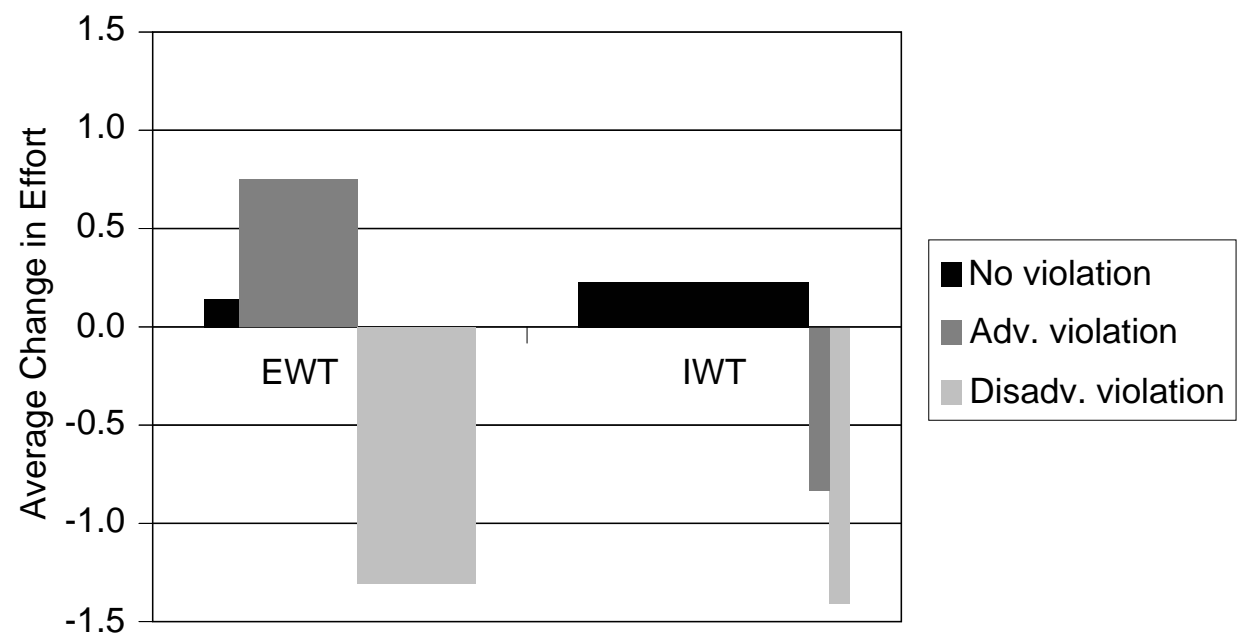

Figure 5: Magnitude of effort reactions. The average change in effort from period $t$ to period $t+1$ is shown given that the agent experienced no norm violation, an advantageous violation or a disadvantageous norm violation in period $t$. The width of the bars corresponds to the number of observations.

the respective category (cf. last column of Table 4). After a disadvantageous norm violation, agents in the EWT react strongly. They decrease their effort by 1.30. Their co-worker, experiencing an advantageous norm violation, increases his effort but not as strong. He raises his effort by only $0.75 .{ }^{19}$ The direction of effort change is in line with the frequencies presented in Table 4. This analysis indicates that agents suffer more from a disadvantageous norm violation than from an advantageous violation. Thus the combination of a disadvantageous and an advantageous norm violation translates into non-monetary incentives that lead to an overall decrease in efforts.

As already observed above, in the IWT both groups of agents experiencing a norm violation decrease their effort. When reciprocity is not violated agents tend to keep their effort constant or even slightly increase it. We performed the same robustness checks as for the analysis of Table 4 . All the alternative specifications yield results similar to the baseline specification depicted in Figure 5.

Result 5: Agents' reactions to a violation of reciprocity are asymmetric: the negative reaction of the disadvantaged agents is stronger than the positive reaction of the advantaged agents. This asymmetry in agents' reactions results in an overall negative time trend in efforts for the EWT and in the strong treatment difference in effort.

The equal wage treatment leads to frequent norm violations. Agents experience the equal wage scheme as less fair. ${ }^{20}$ Interestingly, even the principals consider the equal

\footnotetext{
${ }^{19}$ The difference is statistically significant (Wilcoxon test of the absolute values: $p=0.01$ ).

${ }^{20}$ Note that the treatment effect cannot be explained by profit inequalities per se. The absolute
} 
wage scheme as less fair. In the post-experimental questionnaire, principals are presented three hypothetical game situations that include effort choices, wage choices, and the resulting payoffs for all players. They are asked whether they consider the resulting allocation as just. One of the three situations reflects their own average behavior in the experiment. ${ }^{21}$ The principals do not know that they are facing their own past decisions when answering this question. $63 \%$ of the principals in the IWT consider their own decisions fair while only $38 \%$ of the principals in the EWT share this view (Mann-Whitney test on matching group shares: $p=0.03$ ).

Summarizing, one can say that non-monetary incentives differ between the treatments. The equal wage institution forces the principals to violate reciprocity every time efforts are different. These norm violations translate into non-monetary incentives, partly overpowering monetary incentives and causing adverse reactions by the agents. The asymmetry in the strength of reactions to a norm violation, especially the strong negative reaction to a disadvantageous one, is then able to explain the overall negative effort trend and ultimately the low effort levels in the EWT. By contrast, in the individual wage treatment agents perform well since they are content with the fair treatment: the more hard-working agent earns almost always more than his co-worker. Principals use reciprocity forcefully as an incentive device, inducing high performance of agents. Thus, all parties gain in monetary and non-monetary terms. The individual wage scheme is not only more profitable but also experienced as fairer.

\subsubsection{Simulation with reciprocal agents}

We have seen so far that the presence of reciprocal agents in combination with the frequent violations of reciprocity in the EWT are able to explain the treatment difference. In order to further illustrate how institutions and reciprocity interact, we take our previous findings on agents' period-to-period reactions and link them to the aggregate dynamics in the experiment. We do so by simulating agents' behavior with a simple "reciprocity adjustment" rule. In this simulation, all agents are assumed to derive utility from money, but to also suffer from violations of a norm of reciprocity. When deciding about their effort in a given period, the simulated agents therefore compare their effort and profit in the previous period with the effort and profit of their co-worker in that period. According to the comparison along these two dimen-

differences between co-workers' payoffs are not significantly different between treatments (IWT: 6.47, EWT: 7.14, Mann-Whitney test: $p=0.29$ ) but the sign differs: in the IWT, the harder working agent earns more, while the opposite is true in the EWT. Apparently, different profits are not considered as unfair as long as the hard-working agent gets the higher payoff.

${ }^{21}$ This situation was constructed as follows: We calculated the average effort of the higher-effort and of the lower-effort providers that the principals actually faced during the experiment. We then took the average of the wages the principals paid to the two groups. Finally, we calculated hypothetical payoffs for all three "average" players by considering the costs of the average efforts. 
sions, four reactions can be distinguished for the simulated agents. (i) For an agent who had a higher effort and a higher profit, reciprocity is not violated and the pecuniary comparison is also advantageous for him, so he keeps his effort constant. (ii) For an agent who exerted a lower effort and got a lower profit, the norm of reciprocity is satisfied but profit maximization is not, thus he partly adjusts his effort in the direction of his co-worker's effort, i.e., he chooses an effort $\left(e_{i, t}+e_{j, t}\right) / 2$. (iii) An agent with higher effort and lower profit feels exploited as he suffers from a disadvantageous norm violation. Thus he adjusts his effort fully and chooses $e_{j, t}$. (iv) Finally, for an agent with lower effort and higher profit the norm violation is advantageous, thus the resulting utility is higher than in case (iii). He chooses an effort $\left(e_{i, t}+e_{j, t}\right) / 2$. The reactions in cases (i) to (iv) are in line with the period-to-period reactions presented in Table 4 and Figure 5.

In the simulation, we use actual effort data from the experiment only for the first period. The subsequent effort decisions are based on the simulated profits and simulated efforts of the previous period. The simulated principals pay the average wage for a given effort (IWT) or the average wage sum for a given effort sum (EWT) as calculated from the experimental data. Profits are then calculated as wage minus cost of effort exertion. We use the same matching protocol as in the experiment.

Figure 6 shows how effort choices evolve over time in the experimental data and in the simulations. The simulations 'EWT sim' and 'IWT sim' trace the real data very well and are able to reproduce the large effort difference between treatments. In the individual wage simulation, efforts increase like the real efforts although the slight downward trend in the second half of the experiment cannot be reproduced. Efforts in the equal wage simulation constantly decrease down to an effort level slightly above 3 in the final period. This pattern is very similar to the dynamics in the real data.

We performed several robustness checks of the simulation. To check how the first period efforts influence the result, we initialized the EWT simulation with the first period efforts of the IWT agents and the IWT simulation with EWT-first-periodefforts. The dynamics are very similar to the baseline specification: in the IWT simulation, agents steadily increase their efforts while they decrease their efforts in the EWT simulation. Also other first-period-effort-vectors do not change the general result of the simulation as long as efforts are sufficiently heterogeneous. If agents exerted the same effort already in the first period, equal wages would not violate reciprocity and efforts would not decrease over time. The rules specified for cases (i) to (iv) do impact the result, though not all with the same strength. While the rules for case (ii) and (iv) can be changed without altering the qualitative result of the simulation very much, it is crucial to keep the rules for case (i) and (iii) similar to our baseline specification. The treatment difference can only be reproduced in this setup if the agents revise their effort decision downwards after experiencing a disadvantageous norm violation (case 
(iii)) and if they continue to exert high efforts when they earn money and feel treated fairly (case (i)).

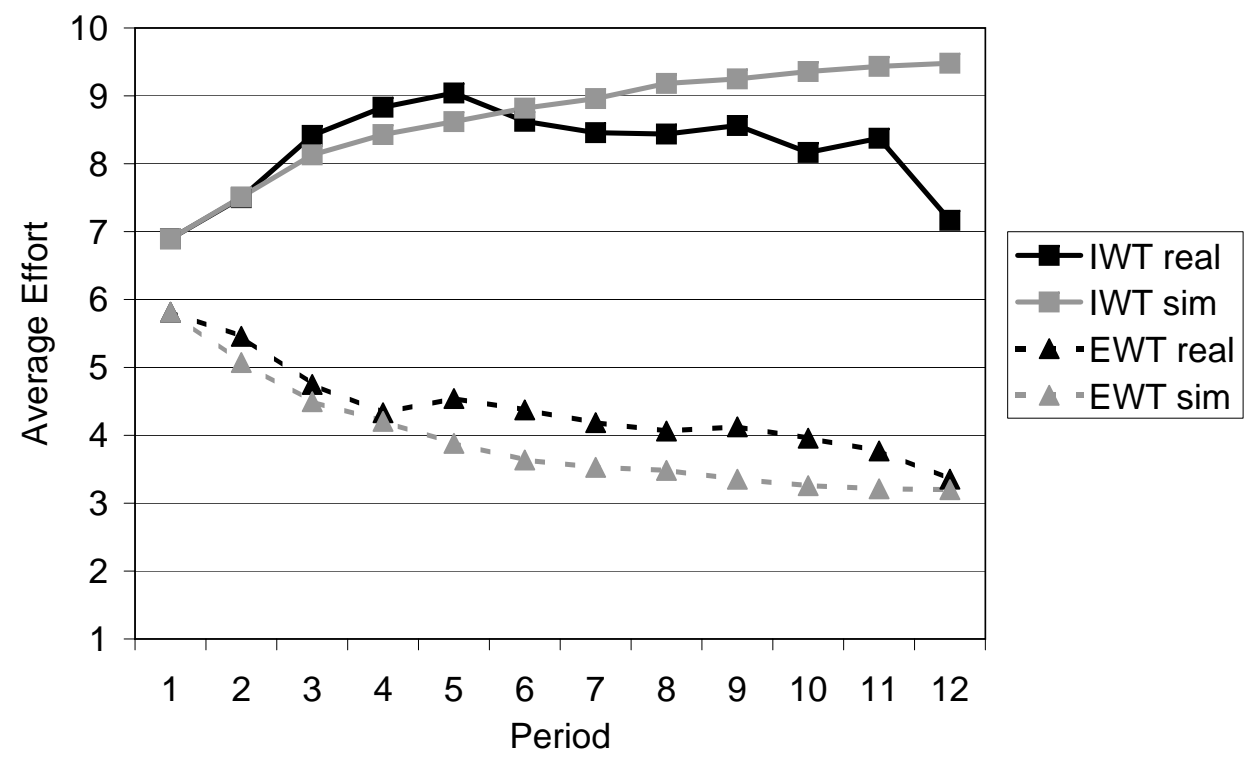

Figure 6: Simulation with reciprocal agents.

Note that the pivotal agent is different between the simulated treatments: in the equal wage simulation the norm of reciprocity is not fulfilled when agents choose different effort levels. In these cases in the simulation, the agent with the higher effort will fully adjust his effort in the direction of his co-worker's effort while the co-worker will increase his effort level only to the average effort of the last period. In the EWT simulation, the average effort therefore converges to the lowest first period effort as agents are subsequently matched together: the low-effort providers are pivotal. By contrast, in the IWT the high-effort providers have the decisive impact on the overall outcome. The norm of reciprocity is mostly fulfilled in the IWT. Thus, the agent with the higher effort keeps his effort constant while his co-worker adjusts his effort. The average effort therefore converges to the highest first period effort. We will analyze this point in more detail in the next section.

Result 6: Simple simulations based on agents who have preferences for money and reciprocity are in line with the efforts observed in the experiment and are able to reproduce the observed treatment effect.

\subsection{Dynamics of high- and low-effort providers}

As already seen in Figure 2, subjects exhibit a substantial degree of heterogeneity with respect to effort provision. In the following, we analyze if the agents who are most or least willing to exert effort are affected differently by the two payment modes at hand. A common informal argument claims that equal wages will be especially detrimental 
to the motivation of high performers (e.g., Milgrom and Roberts (1992), p. 419) but clean empirical evidence is scarce. Furthermore, it is unclear how weakly motivated agents react to equal or individual wages. We also address the question whether high and low performers impact the overall results differently in the two treatments. The simulations presented in the previous section suggest that this could indeed be the case: in the EWT simulation, the low-effort providers are decisive for the final outcome while it is the high-effort providers in the IWT simulation.

To analyze these questions in the experimental data we classify agents according to their effort decision in the first period. We define the agent with the highest first-period effort in each matching group as "high-effort provider" and the agent with the lowest effort as "low-effort provider". ${ }^{22}$ This type definition is chosen because when agents decide on their effort in the first period, they do not have any information about the behavior of other subjects and all learning and coordination processes occur after this initial effort choice. Thus first-period effort is likely to be a good proxy for the intrinsic willingness of a specific agent to exert effort. If some of the subjects are intrinsically inclined to exert high efforts they should show up in the group of high-effort providers. In contrast, if some of the subjects are intrinsically inclined to exert low efforts they should show up in the group of low-effort providers.

In Figure 7 we follow the high-effort providers and low-effort providers in both treatments and show their effort decisions over time. In the first period, the groups of high-effort providers and the groups of low-effort providers are close together across treatments. ${ }^{23}$ This changes completely over the course of the 12 periods. In the individual wage treatment, high-effort providers continue to provide high effort levels. Low-effort providers increase their efforts dramatically up to the level of the high-effort providers and even higher in the last periods. In the equal wage treatment, the dynamics are reversed. Here, the low-effort providers keep their effort provision constant and the high-effort providers reduce their efforts to the level of the low-effort providers. ${ }^{24}$ Put simply, the "good" agents push the "bad" agents up under individual wages while under equal wages the "bad" ones pull the "good" ones down.

These dynamics underline the importance of the different non-monetary incentives in-

\footnotetext{
${ }^{22}$ If more than one agent chooses the highest or lowest effort in the first period, the subsequent effort decisions of these agents are averaged.

${ }^{23}$ In the first period, effort levels are not significantly different between treatments for high-effort providers (Mann-Whitney test: $p=0.14$ ) while they are close together but different for the loweffort providers (Mann-Whitney test: $p=0.03$ ). Within treatments, the high-effort and low-effort providers choose statistically different effort levels in the first period (Wilcoxon signed rank test: $p=0.01$ (IWT), $p=0.01(\mathrm{EWT})$ ).

${ }^{24}$ In the last six periods, effort levels are not different within treatments (Wilcoxon signed rank test: $p=0.67$ (IWT), $p=0.78$ (EWT)) while they differ between treatments (Mann-Whitney test: $p<0.01$ (high-effort providers), $p<0.01$ (low-effort providers)).
} 


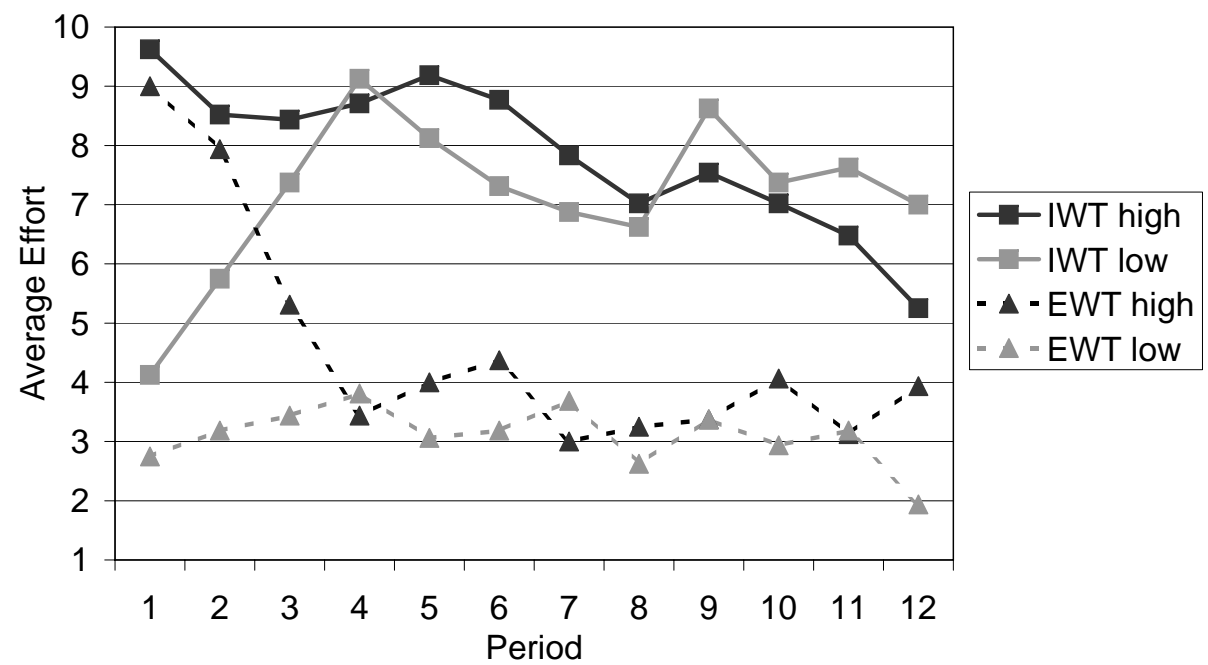

Figure 7: Effort decisions of high-effort and low-effort providers. In each matching group, the agent with the highest (lowest) effort in the first period is defined as the high (low)-effort provider.

duced by the two wage setting institutions. Remember that agents face similar monetary incentives in both treatments. Wage equality often violates reciprocity. Agents in this treatment who are in principle willing to exert high levels of effort get frustrated and lower their efforts. On the contrary, under individual wages where reciprocity is intact, good performance spreads. These results suggest that choosing a wage scheme also influences the social dynamics between the agents. ${ }^{25}$ In our experiment, individual wages lead to positive dynamics since agents orient themselves to the most hard-working agents. In contrast, the equal wage scheme focuses agents' attention on the least motivated agents.

Result 7: The pivotal agent is different between treatments: in the IWT the initially low-effort providers align with the high-effort providers over time. In the EWT the initially high-effort providers align with the low-effort providers over time.

\section{Conclusions}

In this paper, we studied the interaction of reciprocity with different wage schemes. More specifically, we analyzed how effective equal wages are in an environment where contract enforcement solely relies on reciprocity. In our experiment, one principal is matched with two agents. The principal pays equal wages in one treatment and can set individual wages in the other. The use of equal wages elicits substantially lower efforts and efficiency in spite of similar monetary incentives for the workers under both

${ }^{25}$ See Manski (2000) for a discussion of social interaction effects. 
wage schemes. In particular, exerting high effort pays off in both settings. The strong treatment difference is driven by subjects' reciprocal preferences and the fact that reciprocity is frequently violated in the equal wage treatment. This is not the case in the individual wage treatment, as principals set wages mostly in line with reciprocity.

Our results have a number of implications, both for the advancement of existing theories and for the design of wage schemes in practice. First of all, it is doubtful whether wage equality can be reconciled with the use of reciprocity to enforce incomplete contracts. Our findings rather suggest that the possibility to individually sanction bad performance and reward good performance is a crucial prerequisite to make reciprocity the powerful enforcement device it has proven to be in many bilateral interactions. The performance of agents in the individual wage treatment shows how effective reciprocity can be: although explicit contract enforcement is absent, $80 \%$ of the possible efficiency gains are realized.

Second, while it is well-known that equal wages can distort monetary incentives, in our experiment they are also perceived as less fair and thus efficiency decreasing, even though the monetary incentives are qualitatively not affected. This holds in particular because agents differ in their performance. It may thus be oversimplifying to argue that equal wages lead to less envy and therefore higher work morale, as it is frequently done in the political discussion.

Third, in practice the discretion to individually reciprocate good performance of subordinates does not have to be in monetary terms. Non-monetary benefits like extra vacation or awards can be useful devices to motivate workers in this context. These instruments become especially important when it is not possible to wage discriminate on a given hierarchical level, e.g., because the firm's internal pay structure, agreements with a union or legislation dictate wage equality.

The results in this paper should not be interpreted as arguments against wage equality in general. They rather suggest that equal wages come at a cost that has to be weighed against their potential benefits. For example, equal wages are easier to implement than individual wages, and they may encourage peer monitoring and collaboration. The relative importance of these costs and benefits (and also the impact of the workforce's social preferences more generally) is likely to depend on the details of the institutional setting. These include the production technology, the information structure, and the organizational design of the firm. In this paper we presented results for one such setting. Our design provides a simple and parsimonious framework that can successively be enriched to study these aspects in future research. 


\section{References}

Akerlof, George A. (1982): "Labor Contracts as Partial Gift Exchange." Quarterly Journal of Economics, 97:543-569.

Akerlof, George A. and Janet L. Yellen (1990): "The Fair Wage-Effort Hyothesis and Unemployment." Quarterly Journal of Economics, 105:255-283.

Babcock, Linda, Xianghong Wang and George Loewenstein (1996): "Choosing the Wrong Pond: Social Comparisons in Negotiations That Reflect a Self-Serving Bias." Quarterly Journal of Economics, 111:1-21.

Baker, George P., Michael C. Jensen and Kevin J. Murphy (1988): "Compensation and Incentives: Practice vs. Theory." Journal of Finance, 43:593-616.

Bartling, Björn and Ferdinand von Siemens (2004a): "Efficiency in Team Production with Inequity Averse Agents." Working Paper, University of Munich.

Bartling, Björn and Ferdinand von Siemens (2004b): "Inequity Aversion and Moral Hazard with Multiple Agents." Working Paper, University of Munich.

Bewley, Truman (1999): Why Wages Don't Fall During a Recession. Harvard University Press, Cambridge, MA.

Bowles, Samuel and Yongjin Park (2005): "Emulation, Inequality, and Work Hours: Was Thorsten Veblen Right?" The Economic Journal, 115:F397-F412.

Charness, Gary and Peter Kuhn (2005): "Pay Inequality, Pay Secrecy, and Effort: Theory and Evidence." NBER Working Paper, 11786.

Clark, Andrew, David Masclet and Marie-Claire Villeval (2006): "Effort and Comparison Income: Survey and Experimental Evidence." GATE Working Paper, 06-01.

Clark, Andrew E. and Andrew J. Oswald (1996): "Satisfaction and Comparison Income." Journal of Public Economics, 61:359-381.

Demougin, Dominique and Claude Fluet (2003): "Group vs. individual performance pay when workers are envious." CIRPÉE Working Paper.

Dufwenberg, Martin and Georg Kirchsteiger (2004): "A Theory of Sequential Reciprocity." Games and Economic Behavior, 47:268-298.

Easterlin, Richard A. (2001): "Income and Happiness: Towards a Unified Theory." The Economic Journal, 111:465-484. 
Erev, Ido, Gary Bornstein and Rachel Galili (1993): "Constructive Intergroup Competition as a Solution to the Free Rider Problem: A Field Experiment." Journal of Experimental Social Psychology, 29:463-478.

Falk, Armin and Urs Fischbacher (2006): "A Theory of Reciprocity." Games and Economic Behavior, 54:293-315.

Fehr, Ernst and Armin Falk (2002): "Psychological Foundations of Incentives." European Economic Review, 46:687-724.

Fehr, Ernst and Simon Gächter (1998): "Reciprocity and Economics: The Economic Implications of Homo Reciprocans." European Economic Review, 42:845-859.

Fehr, Ernst and Simon Gächter (2000): "Fairness and Retaliation: The Economics of Reciprocity." Journal of Economic Perspectives, 14:159-181.

Fehr, Ernst, Simon Gächter and Georg Kirchsteiger (1997): "Reciprocity as a Contract Enforcement Device: Experimental Evidence." Econometrica, 65:833-860.

Fehr, Ernst, Georg Kirchsteiger and Arno Riedl (1993): "Does Fairness Prevent Market Clearing? An Experimental Investigation." Quarterly Journal of Economics, 108:437-460.

Fehr, Ernst, Alexander Klein and Klaus M. Schmidt (forthcoming): "Fairness and Contract Design." Econometrica.

Fehr, Ernst and Klaus M. Schmidt (1999): "A Theory of Fairness, Competition and Cooperation." Quarterly Journal of Economics, 114:817-868.

Fehr, Ernst and Klaus M. Schmidt (2003): "Theories of Fairness and Reciprocity - Evidence and Economic Applications." In Dewatripont, M., L. Hansen and St. Turnovsky, editors, Advances in Economics and Econometrics - 8th World Congress, Econometric Society Monographs. Cambridge University Press, Cambridge.

Fischbacher, Urs (1999): "z-Tree - Zurich Toolbox for Readymade Economic Experiments - Experimenter's Manual." IEW Working Paper, 21.

Gneezy, Uri (2006): "Bonuses versus Predetermined Wages: A study of Incentives and Reciprocity." mimeo.

Hannan, R. Lynn, John H. Kagel and Donal V. Moser (2002): "Partial Gift Exchange in an Experimental Labor Market: Impact of Subject Population Differences, Productivity Differences, and Effort Requests on Behavior." Journal of Labor Economics, 20:923-951.

Holmström, Bengt (1982): "Moral Hazard In Teams." Bell Journal Of Economics, 13:324-340. 
Itoh, Hideshi (2004): "Moral Hazard and Other-Regarding Preferences." Japanese Economic Review, 55:18-45.

Knez, Marc and Duncan Simester (2001): "Firm-Wide Incentives and Mutual Monitoring at Continental Airlines." Journal of Labor Economics, 19:743-772.

Layard, Richard (2005): "Rethinking Public Economics: The Implications of Rivalry and Habit." In Bruni, Luigino and Pier Luigi Porta, editors, Economics and Happiness, pages 147-170. Oxford University Press.

Lazear, Edward P. (1989): "Pay Equality and Industrial Politics." Journal of Political Economy, 97:561-80.

Loewenstein, George, Leigh Thompson and Max Bazerman (1989): "Social Utility and Decision Making in Interpersonal Contexts." Journal of Personality and Social Psychology, 57:426-441.

Manski, Charles F. (2000): "Economic Analysis Of Social Interactions." Journal of Economic Perspectives, 14:115-136.

Maximiano, Sandra, Randolph Sloof and Joep Sonnemans (forthcoming): "Gift Exchange in a Multi-Worker Firm." Economic Journal.

Medoff, James L and Katharine G Abraham (1980): "Experience, Performance, and Earnings." The Quarterly Journal of Economics, 95:703-36.

Milgrom, Paul and John Roberts (1992): Economics, Organization and Management. Englewood Cliffs, New Jersey: Prentice Hall, 1st edition.

Neumark, David and Andrew Postlewaite (1998): "Relative Income Concerns and the Rise in Married Women's Employment." Journal of Public Economics, 70:157-183.

Prendergast, Canice (1999): "The Provision of Incentives in Firms." Journal of Economic Perspectives, 37:7-63.

Thöni, Christian and Simon Gächter (2005): "Social Interaction in the Workplace." mimeo.

Torgler, Benno, Sascha L. Schmidt and Bruno S. Frey (2006): "Relative Income Position and Performance: an Empirical Panel Analysis." IEW Working Paper, 268. 